\title{
A qualitative exploration of intentional nursing round models in the emergency department setting: investigating the barriers to their use and success
}

\author{
Kate Kirk and Ros Kane
}

Aims and objectives. This research aimed to investigate the use of intentional rounding within in the emergency department setting through exploration of the staff nurse experience. The focus was its implementation at a large teaching hospital in England.

Background. Research into the use of intentional rounding in any area of practice is minimal in the UK; however, a broader evidence base comes from America. The majority of this research supports the notion of intentional rounding for improved patient care and outcomes. Research from the UK is generally more contested. There is less literature on using intentional rounding specifically in the emergency department setting.

Design. Qualitative methodological approach.

Methods. Semi-structured interviews $(n=5)$ were completed with staff nurses working within an emergency department. A purposive sampling technique was used for recruitment. The data was then analysed using 'Framework Method of Qualitative Analysis' (Spencer et al. 2014).

Results. The findings were categorised into four headings: (1) Improved patient experience, (2) Current unmanageability, (3) Adapting for the emergency department, (4) Benefits on achieving quality indicators and targets.

Conclusion. The findings show that although staff felt the introduction of intentional rounding techniques could lead to improvements in patient safety and overall care experience, they also identified a range of difficulties and adaptations needed to ensure its success within this acute care environment.

Relevance to clinical practice. The research offers an insight into the staff's perceptions of using intentional rounding and also explains the practical difficulties faced by the nursing staff with potential suggestions that may help to address these problems. Benefits include more open communication between staff and patients and potentially more timely response to patient need, which positively impacts levels of safety and satisfaction. Barriers include lack of staff engagement, and the environmental factors and pressures, within the ED setting.

Key words: hourly rounding, intentional rounding, nursing practice, patient comfort rounds, patient safety, patient satisfaction, quality of care
What does this paper contribute to the wider global clinical community?

- A qualitative study which is aimed at understanding the use of nurse rounding techniques in the emergency department setting.

- The work aims to contribute to the gap in the literature surrounding nurse rounding, more specifically within this specialism.

- Consequently, this offers a platform for discussion between health care professionals and suggests future research opportunities and practice development.
Authors: Kate Kirk, BSc, Staff Nurse, PhD Student, University of Nottingham, Nottingham; Ros Kane, PhD, MSc, RGN, Principal Lecturer, School of Health and Social Care, College of Social Science, University of Lincoln, Lincoln, UK
Correspondence: Kate Kirk, University of Nottingham, Nottingham, NG8 1BB, UK. Telephone: 01158466602

E-mails: lixklk@nottingham.ac.uk 


\section{Introduction}

The quality of nursing care in the National Health Service (NHS) has recently been under much scrutiny, particularly following the publication of a series of high profile reports outlining inadequacies of provision in several settings (Berwick 2013, Cavendish 2013, Francis 2013, Keogh 2013). Concerns raised about poor standards have refocused attention towards a need to ensure fundamental aspects of nursing care are delivered effectively. Understanding and delivering high quality patient experience is a key indicator of success detailed clearly in a number of documents pertaining to quality health care in the UK: the National Institute for Health Care Excellence (NICE) quality standard: Patient Experience in adult NHS services (QS15) being one example. How highquality care is delivered and achieved at local level, however, remains a matter of ongoing debate.

The concept of intentional rounding was introduced to the UK in 2006 (Bartley 2011) but started to become more prevalent following the publication of the Francis and Keogh reports which led to intervention by the British Prime Minister, who publicly supported the campaign for intentional rounding (Kendall-Raynor 2012). It was subsequently widely introduced in an attempt to address many of the issues surrounding patient safety, compassion and quality of care.

Intentional rounding is also referred to as 'hourly rounding', 'nurse rounding' and 'comfort rounding' (Hutchings et al. 2013, Forde-Johnston 2014) and is a structured approach, whereby nurses conduct regular checks (in some organisations every two hours) on patients to proactively assess and manage their individual needs (Lucas \& Ahmad 2010, Bartley 2011, Fitzsimons et al. 2011, Mason 2012, Harrington et al. 2013, Hutchings et al. 2013, Shepard 2013, Forde-Johnston 2014). The process 'meaningful' interaction with patients at frequent intervals (Hutchings 2012). It has signalled a return to the 'basics' of nursing care (Castledine et al. 2005). At these intervals, patients are asked a set of guiding questions, often based around their needs relating to comfort, nutrition, hygiene and pain management. These prompts are aimed at guiding shared decision-making whereby staff respond to the answers given by the patient and then complete relevant documentation, agreeing a further time interval for the next intentional rounding episode.

It is argued that intentional rounding places patients at the heart of the ward routine including the acknowledgement of their preferences and anticipation of their needs (Harrington et al. 2013). It also encourages relationship development with the patient and their family (Fitzsimons et al. 2011) while also promoting visibility of nursing staff, which is said to increase patient satisfaction (Lyons et al. 2015). Gillen (2012) summarised intentional rounding as: 'about being highly visible to patients at least every hour and providing personalised care at that point should it be required'.

This research has been undertaken to investigate the use of an intentional rounding model in practice, in this case, specifically within the Emergency Department (ED) setting. Potential barriers and benefits to using an intentional rounding model in this speciality were explored, with the aim of understanding whether improvements to the rounding process could be introduced, to improve the feasibility and effectiveness of delivery.

\section{Research question}

What are the barriers and facilitators, as perceived by qualified nurses, to the effective implementation of hourly intentional nurse rounding in the emergency department setting?

\section{Aims}

Within this specific setting, the aims of this research were to:

- Explore the experiences of nurses involved in the delivery of intentional nurse rounding,

- Explore nurses' perceived benefits and limitations of nurse rounding.

\section{Background}

Intentional nurse rounding is a controversial topic which has received much media coverage in the UK. The academic literature on the concept, however, largely originates from the USA, though studies from elsewhere are now emerging.

There is a body of literature which suggests that implementation of intentional nurse rounding results in improved patient experience. Several studies, as detailed below, have explored its effect on clinical outcomes such as levels of patient satisfaction, the incidence of call bell use, patient falls, pressure ulcer development and patient complaint.

There is evidence that intentional rounding can result in improvement in patient satisfaction (Bartley 2011, Saleh et al. 2011, Baker 2012, Dix et al. 2012, Kessler et al. 2012, Durazo et al. 2014). In an evidence review of 
research into patient satisfaction relating to hourly rounds, Hutchings et al. (2013) reported improvements in overall patient satisfaction in eight of nine studies. Patients were likely to recommend the hospital and were satisfied with anticipation of, and attention to, personal needs (Hutchings et al. 2013). These findings are re-iterated in a further literature review by Forde-Johnston (2014).

Several studies have explored the impact of intentional rounding on the use of patient call bells. Many show positive outcomes (Woodard 2009, Baker 2012, Braide 2013, Hutchings et al. 2013, Durazo et al. 2014) with for example, Harrington et al. (2013) demonstrating a 50\% reduction in use, and Hutchings et al. (2013) a 32\% fall. Data from the UK indicate a significant reduction from an average of eight to just one call per hour (Dix et al. 2012).

Research has also investigated the influence in the introduction of intentional rounding on the incidence of falls by patients and several studies have demonstrated a reduction (Kessler et al. 2012, Sherrod et al. 2012, Braide 2013, Durazo et al. 2014). Indeed Braide (2013) demonstrated a $36 \%$ decrease in patient falls within one month of the introduction of intentional rounding. However, in a secondary evidence review, Hutchings (2012) identified conflicting evidence regarding falls. Although some studies did indicate the beneficial impact of intentional rounding some indicated either no change in the incidence of falls and another actually observed an increase (Bourgault et al. 2008).

Another clinical outcome to have been investigated is the occurrence of pressure ulcers following the introduction of intentional rounding, with evidence that the introduction of rounding can result in a reduction in pressure ulcer development (Saleh et al. 2011).

Research has demonstrated evidence of greater efficiency associated with intentional rounding; this includes increased nurse and patient contact, which facilitates the building of trust between nurses and patients (Aitken et al. 2011, Fitzsimons et al. 2011). As a consequence, there is an increase in patients' positive perception of care (Durazo et al. 2014), reduced patient anxiety, increased patient comfort (Fitzsimons et al. 2011) and better pain management (Bartley 2011).

Specifically within the ED research has indicted that intentional rounding contributes to a reduction in the number of patients who leave the department before they have been assessed by a doctor (or 'did not wait'). Durazo et al. (2014) showed quicker discovery of and intervention with health complications while Dix et al. (2012) found that rounding resulted in more timely response rates by staff. All of these factors combine to result in a reduction in the number of formal complaints from patients (Braide 2013).
In addition to benefiting patients, there is growing evidence to show positive outcomes from intentional rounding for staff, including improved relationships with one another. There is evidence for example, that intentional rounding facilitates better staff communication, encouraging team working and rapport (Generals \& Tipton 2008) and contributes to creating a rewarding, enriching environment of trust (Blakley et al. 2011). Particularly prevalent in the literature are reports of increased nurse satisfaction with care (Lucas \& Ahmad 2010, Dix et al. 2012, Braide 2013, Harrington et al. 2013, Hutchings et al. 2013).

A key finding from a comprehensive review of the evidence, Forde-Johnston (2014) found that different clinical areas implement rounding in different ways (Lucas \& Ahmad 2010, Bartley 2011, Dix et al. 2012, Braide 2013, Harrington et al. 2013, Hutchings et al. 2013), with, for example, one or two-hourly rounding or a combination of both. A number of factors might influence frequency of rounds including levels of patient acuity or time of day (Harrington et al. 2013), staffing mix and identified member responsible for managing rounding (Woodard 2009).

Different methods of documenting rounding episodes have been reported; one of which includes the use of a 'rounding clock' (Hutchings et al. 2013). Here, a clock is given to each patient at their bedside, it is then adjusted accordingly after an episode of intentional rounding has been completed. This gives an indication to the patient when the nursing staff will return to complete the next session of rounding (Hutchings et al. 2013).

Despite the above emerging evidence about the impact of rounding, research relating to the feasibility and logistics of implementing it in different settings remains patchy and evidence to support it is limited (Hunt 2012), leading to suggestions that, a more in-depth evidence base is needed (Snelling 2013a). Forde-Johnston (2014) identified the paucity of empirical research from the UK on its feasibility and effectiveness, particularly within specific clinical settings. Further research is now needed in other specialty areas. Very little evidence exists to guide the optimal models of implementation and there is a particular gap in research specifically examining the feasibility of implementing intentional rounding in the emergency care setting.

\section{Methods}

\section{Ethics}

Ethics approval was sought through the University of Lincoln ethics committee and granted on $14^{\text {th }}$ April 2014. 


\section{Design}

A qualitative research methodology was selected, as an appropriate approach to learn about individuals' perceptions, perspectives and beliefs (Ormston et al. 2014) about the benefits and limitations to intentional rounding. Consideration was given to the complex and challenging emergency department setting when a methodology was selected. The decision was made to undertake qualitative interviews as the data collection method for this study, largely because of their ability to collate and capture in-depth qualitative data which has the opportunity to explore individual insights from key respondents (O'Leary 2010).

The thoughts and opinions of qualified staff nurses were sought via interview. Respondents had a variety of different nursing backgrounds and all had experience of applying and using an intentional rounding model within the emergency department setting. Further demographics are detailed in Table 1 below.

\section{Setting}

The study was set within the emergency department (ED) of a busy teaching hospital in England, which sees an average of 450 patients a day (NHS England 2015). It employs around 250 staff including doctors, nurses, Emergency Nurse Practitioners (ENPs), Emergency Physiotherapy Practitioners (EPPs) and Emergency Department Assistants (EDAs).

\section{Data collection}

\section{Sample and recruitment}

The sample of emergency department staff nurses was selected using a nonrandom, purposive sampling approach. Purposive sampling was used to ensure that the respondents were able to give an insight into a specific set range of perceptions, perspectives and beliefs. Purposive sampling also involves decisions regarding each respondents' experience,

Table 1 Below outlines the details of the sample of respondents

\begin{tabular}{lllll}
\hline & & & $\begin{array}{l}\text { Length of } \\
\text { employment } \\
\text { at the } \\
\text { ED (years) }\end{array}$ & $\begin{array}{l}\text { Current } \\
\text { experience } \\
\text { working as } \\
\text { a qualified } \\
\text { nurse (years) }\end{array}$ \\
\hline Respondent 1 & Female & Staff nurse & 1 & 3 \\
Respondent 2 & Female & Staff nurse & 1 & 4 \\
Respondent 3 & Female & Staff nurse & 3 & 5 \\
Respondent 4 & Female & Staff nurse & 2 & 4 \\
Respondent 5 & Female & Staff nurse & 3 & 10 \\
\hline
\end{tabular}

expertise, knowledge, background and ability to give applicable data during interview (O'Leary 2010).

All of the respondents interviewed were qualified staff nurses working within the same emergency department, which ensured they had the appropriate knowledge base and experience of intentional rounding. Effort was also made to recruit nurses from a variety of levels and length of experience working within the emergency department setting.

During the recruitment process, additional consideration was given to potential constraints and feasibility of completing the interviews. Effort was therefore made to ensure that this did not affect the sample selection. The option of holding the interviews outside of the working environment was offered to each individual participant, as was the option of supplying nursing cover for the duration of the interview. It was hoped that by working with individuals in a flexible way would facilitate recruitment of a diverse sample.

\section{Conducting the interviews}

Five in-depth interviews were conducted, each lasted around 30 minutes. With consent, all interviews were transcribed verbatim. Each participant was interviewed individually, face to face, in a variety of quiet and peaceful destinations, selected by each participant. Anonymity was maintained both on the tape recording and on the transcript. Respondents were labelled simply A-E.

Although the interviewer held objectivity (O'Leary 2010) in terms of the questioning approach during the interviews, the importance of gaining rapport and trust with the respondents, developing 'open' lines 'of communication' (O'Leary 2010), through an informal style, was of great importance in data collection. This informal approach appeared to work towards facilitating open answers and an effective relationship between interviewer and interviewee.

\section{Data collection tools}

Prior to commencement of the interviews, each individual was given a participant information sheet which outlined the research question, explained the background of the study and outlined the aims. The documentation covered the plan for the interview, including its length and the type of questions which would be asked. The participant information sheet also gave the opportunity for the participant to ask any questions.

The respondents were also asked to read and sign a consent form which highlighted to what consent was being given, including the option of withdrawing from the study at any time without giving notice or a reason. 
A topic guide was also compiled to aid data collection. This outlined the key ideas and questions that were asked in the interview. The questions included in the topic guide are shown in Table 2 below.

\section{Data analysis}

The interviews were analysed using the 'Framework' method of qualitative data analysis by Spencer et al. (2014). This method which is well established as a tool for qualitative researchers, involves the following five steps:

1 Familiarisation with the material

2 Identifying a thematic framework (and developing a coding frame)

3 Indexing (applying codes to the data)

4 Charting (on a spreadsheet to allow analysis within and between themes using data from all the interviews)

5 Mapping and interpretation

The detailed process is systematically categorised into five individual stages outlined above and elaborated on below.

Initially there was a familiarisation period in which relevant topics to the research question were identified. This first stage of the process involved the researcher 'immersing' themselves in the data, ensuring that the following stages were 'grounded' and 'supported' by the data. Following this, the initial topic headings were sorted and categorised into themes and sub-themes and an initial thematic framework was formed. Consequently, in the next phase of the process, the data were labelled and applied to the appropriate label or heading using the framework, for deeper analysis. In some cases involved the amendment of labels. Finally, it was felt in this project, that it was helpful to use the data summary and display framework, which sorted information into a visual, organised matrix for more structured method to aid analysis and interpretation (Spencer et al. 2014).

Table 2 Content of the topic guide used to guide the semi-structured interviews

General introduction to the research and purpose of the interview

Could you please share with me your general experiences, thoughts and feelings on the concept of hourly rounding in the Emergency Department, and if applicable, elsewhere?

How well do you feel this model of nursing works in the

Emergency Department setting? Please elaborate

Do you feel there are any benefits to using such a model in the Emergency Department setting? Please elaborate

Do you feel there are any limitations to using such a model in the Emergency Department setting? Please elaborate

\section{Results}

The following four key themes were identified: Improved patient experience; Current unmanageability; Adapting for the emergency department; Benefits on achieving quality indicators and targets.

\section{Improved patient experience}

All respondents made clear their opinions regarding the impact of intentional rounding on improved patient experience. A large amount of focus was on recognising the deteriorating patient and patient safety. More generally it was felt that in relation to improved patient experience, intentional rounding was a 'good idea' (Respondent E) and that there were 'numerous benefits' (Respondent B) to using it. Respondent $\mathrm{C}$ expressed a strong sense that the concept and usage of intentional rounding were much needed in the emergency department. Respondents explained that intentional rounding helped improve care standards in many ways, fundamentally by giving nursing staff the opportunity to recognise if and when a patient's condition was deteriorating, and potentially preventing the need for higher levels of medical intervention or further complications. Respondent $\mathrm{D}$ explained that by using intentional rounding, nurses can 'see if anything is changing about their [patients] condition'. Respondent E echoed this: 'we should be able to identify when patients are deteriorating' and consequently intervene earlier.

Respondents noted further positive impacts of intentional rounding on the patient experience, one of which was that it gave patients an understanding and reassurance about when a staff member would return to see them again, which in turn resulted in better communication and reduced anxiety for the patient. Respondent B felt that it is important that [patients] they are seen in the hour, so they are assured that someone is there to answer their problems and any questions'.

In particular, findings from the interviews repeatedly highlighted the benefit of intentional rounding on the welfare of older and vulnerable patients, who often present to the emergency department with complex needs. Commonly, older patients and those described as more vulnerable need additional essential care such as assistance with using the toilet, nutrition and support with skin and pressure sore prevention. Respondents explained how individuals who need help with activities of daily living are often those who benefit most from intentional rounding. It was also noted, however, that due to their complex needs, at times when large numbers of frail older patients are in the department, 
the intentional rounding process took staff longer time to complete.

The effect of intentional rounding on relatives was raised by two respondents, who reported its potential benefits to relatives, who often feel unsure of what the patient is waiting for and the reasons behind any delays. It was suggested that relatives feel happier because of the added communication intentional rounding brings.

\section{Current unmanageability}

Respondents described how the current process for intentional rounding was unmanageable. Patient volume was highlighted as a clear limitation to successful implementation and this made it 'difficult' and 'near on impossible' to see every patient within an hour. This issue was raised as a recurrent concern by respondents, one in particular stating that 'where it doesn't work is when the volume of patients just exceeds the capabilities of the staff' (Respondent E). Similarly, the impact of excessive patient volume within the emergency department was noted by all of the respondents, as were concerns surrounding the nature of the evolving workload. Respondent A stated: 'I do think a different concept needs to be put in place to allow for the flow rate of patients' within the emergency department.

Comparisons were made between the success rate of using intentional rounding when the department was quieter and at its most busy: 'the difficulty with it is, partly the amount of patients that are there at any one time, when there not a lot of patients, it's very easy to do that round in an hour, when there's a lot, it can be near on impossible really' (Respondent C). Respondents described how they felt the emergency department was very different to the ward setting: 'your patient population is constantly evolving, constantly changing and moving around geographically, it's very difficult to manage' (Respondent B). This therefore proved challenging and problematic when trying to implement intentional rounding in this specific setting.

\section{Adapting for the emergency department}

In response to the difficulties raised above, the respondents discussed their thoughts and feelings on how intentional rounding may be adapted to aid successful implementation within the emergency department setting. Respondents discussed whether intentional rounding was suitable for all patients within the emergency department setting. These points were raised in relation to age and the appropriateness of asking each patient-specific questions every hour. It was felt that younger patients who were able to, may be able to address their own needs. It was felt more appropriate to prioritise intentional rounding with more vulnerable and older patients.

Difficulties surrounding documentation of intentional rounds were also raised by respondents; they explained how it was difficult to sometimes 'get to a computer to document [post round intervention]' (Respondent A). Respondent $\mathrm{B}$ highlighted how it was sometimes challenging to have the opportunity to document intentional rounding in a 'timely manner'. Furthermore, it was suggested by Respondent A, whether a form of paper documentation (which stayed with the patient) would be more appropriate and helpful than use of a centrally located electronic system.

The content, nature and frequency of the intentional rounding episodes were discussed during all of the interviews. Staff highlighted how intentional rounding in the emergency department often focused largely on completing observations at hourly intervals, and less on other patient needs. There was also discussion surrounding the necessity for hourly observations to be completed on every patient in the department. Respondent E noted that 'in a ward environment, it [intentional rounding] seems to be less focus on performing observations.......cos the frequency of observations would be based on what their previous Early Warning Score was, whether it was four hourly, or once daily if they were stable and waiting to go home'.

The need for a review of the staff involved in delivering intentional rounding was also raised. It was felt that currently, the success of intentional rounding is heavily reliant on the role of certain staff members, in particular the EDA (Emergency Department Assistant), who often took on a central role in rounding, completing the process. Respondent E noted that when EDA staff become busy transferring patients to wards and are temporarily absent from the department, implementing intentional rounding hourly becomes more problematic. Respondent A agreed with this, also explaining that relying only on EDA staff is not 'suitable' as they also have their own workload. It was also noted that the task of intentional rounding required a multidisciplinary approach.

The findings showed a clear pattern suggesting that staff felt intentional rounding would need significant adaptation to work successfully in the emergency department; 'I think it [intentional rounding] would have to be modified quite a lot to apply in ED, because it's obviously very different from ward settings'. Specifically, it was noted that during the recent intentional rounding trial period, different methods of implementation had been tried and although staff felt it is important in improving patient safety, a different 
approach is needed for feasible implementation and positive outcomes to be achieved.

Changes in the culture of the emergency department were also recognised by respondents, who noted that staff within the department often operate in a very 'task orientated' way due to the workload demands. In response to this it was suggested that a possible arrangement for implementation may be the allocation of a specific staff nurse (and/or Emergency Department Assistant) whose task was solely the delivery of rounding episodes. The benefits of this approach were felt to be that the staff member delivering the intentional rounding would be able to get to know and build a relationship with their patients. In addition, the level of disturbance to other staff members, who often get pulled away from intentional rounding to other tasks, would be reduced. However, potential drawbacks to this approach were also noted. There was concern that being identified as the sole deliverer of the rounds might not be popular with some staff members and may cause staff disputes. This point was described by Respondent C: 'some nurses might not like to do it, and it could just lead to feuds in that respect. We might have to look at kind of doing it once, once a shift, someone might have to do it for an hour, that might be one way of getting over it'.

\section{Benefits on achieving quality indicators and targets}

Respondents noted that successful implementation of intentional rounding may have a direct impact on the success of the department $(\mathrm{ED})$ in meeting quality indicators - specifically that of the breach target, which is set nationally and aims to assess and treat, then admit or discharge, $95 \%$ of all patients within four hours. Here, respondents explained how ensuring patient care needs are met in a timely manner throughout their stay in the emergency department, potentially reduces the need for further input when it is time to transfer patients to the ward, home or another destination. This was explained by Respondent E: 'things should be done in a timely manner [when using intentional rounding] so with regards breaching, and $\mathrm{um}_{\mathbf{2}}$ the time constraints of ED, patients shouldn't need to go to the toilet, or need pain relief just as you're about to wheel them out of the door'. It was felt that careful management of intentional rounding could have a positive impact on preventing breach of the four hour target. Respondents explained how intentional rounding (or similar), may help to identify and respond to any issues prior to ward transfer, and subsequently have the potential to manage care more efficiently.

\section{Discussion}

The findings show that respondents felt intentional rounding had the potential to improve the experience for patients in the ED. This was particularly so for those who were classed as older or vulnerable. Given that in the UK the number of people aged 85 years and over is set to increase by two-thirds over the next 20 years and that in 20132014 patients over 70 accounted for $16.6 \%$ of attendances to EDs (HSCIC 2015), a figure which is on the increase, it is imperative to work towards more efficient and effective ED care for this population. This is reiterated by others (Banerjee et al. 2013), in particular by a recent report which highlighted the poor quality of care received by older people Ombudsman HS (2011).

Implementing intentional rounding offered opportunities for increased communication opportunities between staff, patients and their relatives. Other researchers have noted the importance of good and open communication and quality care. Indeed timely response to patient need has been identified as a key indicator of patient satisfaction (Ford 2010, Dix et al. 2012). Bourgault et al. (2008) argue that patients equate quality care directly with good communication, and prompt recognition and provision of high-quality care impacts directly on levels of satisfaction (Castledine et al. 2005).

Importantly, it was also found that intentional rounding can lead to increased responsiveness and anticipation of patient need. Intentional rounding also offered a method of recognising patients whose condition was deteriorating such that treatment could be commenced sooner, with potentially better outcomes. There is now emerging evidence from the UK of inadequacies in the management of acute patients in the hospital setting with a focus on methods to improve early detection of deterioration (Mcdonnell et al. 2013). Issues to do with interpersonal communications between hospital staff, inadequate training, poor safety procedures have been identified as significant influences on timely response to deterioration (Subbe \& Welch 2013).

The findings also identified difficulties felt by the respondents in relation to the implementation of intentional rounding in the ED setting. Here, the relationship between patient volume, the ever changing environment and workload within the emergency department were noted as problematic. Staff attitudes and shortages were recognised as a barrier to implementation, showing the limitations and practical problems faced by respondents. 
Other research has outlined the importance of staff attributes to the successful implementation of rounding. Braide (2013) claimed that the extent to which staff appeared to be approachable during a round is likely to influence patient satisfaction. However, the difficulty in engaging staff in intentional rounding was also acknowledged.

Other measures to engage staff have been suggested in the literature. These include involving them in the development of approaches to documentation (Braide 2013, Harrington et al. 2013, Hutchings et al. 2013) and adopting a flexible, inclusive, team approach to the delivery of rounding (Dix et al. 2012, Harrington et al. 2013).

This study raised issues about the most appropriate staff members to be involved in the delivery of rounding. In line with the published literature, there is no standardised norm and variation exists between and within organisations (Braide 2013, Harrington et al. 2013). Practical issues surrounding those staff members involved in intentional rounding were discussed at length (on how it is currently and how it could or should be involving a multidisciplinary approach). To ensure the success of intentional rounding, it is important that staff are convinced of its benefits (Hicks 2015). Dix et al. (2012) argued that staff engagement and understanding of the process were crucial for successful implementation. Reticence to the introduction of new concepts has been reported with the recognition that nurses often view them as involving additional unnecessary work, especially when they feel they already interact with their patients at least hourly (Lowe \& Hodgson 2012, Shepard 2013). This importance of staff compliance to rounding has been discussed in the literature. Kessler et al. (2012) argued that staff strict adherence to the agreed protocol for rounding and nurse-patient interaction was crucial for the achievement of positive outcomes from rounding.

Research from Scotland also demonstrated positive outcomes of rounding and again noted the importance of commitment from on the front line staff (Ciccu-Moore et al. 2014). They argued that successful implementation relies on a systematic and informed team approach: 'the team implementing rounding has to be fully aware of, and committed to, the best standards of nursing practice, otherwise improvement initiatives would be superficial and not yield evidenced success' (Ciccu-Moore et al. 2014, p. 22).

Respondents explained about the culture within this setting and how it could be seen as task orientated. Indeed the concept of rounding remains controversial in some of the academic literature. Modern nursing involves critical thinking, reflection, problem solving and shared decision-making with patients. However, those against rounding claim that it constitutes a move away from empowering nurses and advocates the return to antiquated practices that deskill nurses (Lyons et al. 2015). Indeed Lyons et al. (2015) go on to argue that nursing rounds lead to an expectation that patients will fit into rigid predetermined schedules which in itself may act to undermine the nurse-patient relationship (Lyons et al. 2015).

Berg et al. (2011) argued to the benefits for intentional rounding in contributing to improvements in organisation and workflow. Ford (2010) explained how the reduced use of call bells by patients, in turn contributed to a quieter work place. As a consequence, nurses stress levels were reduced, and they had more time to give to patient care.

Research on the benefit of rounding directly to nursing staff is less conclusive, however, Neville et al. (2012) demonstrated that although nurses recognised benefits to patients and relatives, they were less clear about the direct benefit rounding has on staff and had specific concerns about the time consuming documentation.

Nurses argue for the need to prioritised delivering care to high-acuity patients over maintaining rounding schedules (Deitrick et al. 2012). Issues surrounding the frequency of intentional rounding and the interventions involved during the interaction were also discussed. Because intentional rounding involves standardising in the frequency and way in which nurses interact with their patients, D'Alessio et al. (2010) argue that it offers a more efficient way of working by and results in improved work processes and care delivery, patient satisfaction and safety. However, concern has been expressed about the introduction of rituals and how this could compromise individualised care (Braide 2013, Snelling 2013a, Ciccu-Moore et al. 2014). Others have suggested that staff feel rounding can be patronising due to its implication that nurses require a formal schedule and checklist to be able to deliver care effectively and efficiently (Lowe \& Hodgson 2012, McEwen and Dumpel (2010).

Respondents offered thoughts and ideas on the difficulties they faced and ideas and potential solutions how they may be able to overcome these at a practical level, involving various approached and staff allocation, different documentation methods. Previous research also suggests the need for less documentation relating to intentional rounding (Harrington et al. 2013) to improve efficiency and compliance.

\section{Limitations}

The sample size used within the study is recognised as a limitation and as such we can not be completely confident that data saturation was reached (S.E. Baker and R. 
Edwards, NCRM, Middlesex University and University of Southampton, unpublished). Further research investigating the potential feasibility and benefits of intentional rounding would seek a broader range of staff perspectives. Consequently, there is scope following this study to not only increase sample size but to also extend interviews to include those staff members from various roles within the emergency department. Possibilities of including of EDAs, all levels of qualified nurses and doctors and senior management should be considered.

\section{Conclusion}

This research has explored the potential for use of nurse intentional rounding in the emergency department setting by examining the perceptions, perspectives and beliefs of qualified nurses about the benefits and limitations of its implementation. It begins to address concerns raised by others about the paucity of evidence into the feasibility of intentional rounding and guidance to implementation (Ciccu-Moore et al. 2014) and contributes to debate on its potential benefits.

The findings show that staff feel the introduction of intentional rounding techniques could lead to improvements in patient safety and overall care experience. However, the nurses also identified both a range of difficulties and adaptations needed, to aid the success of rounding in the ED. The research offers an insight into staffs perceptions of using intentional rounding and also explains the practical difficulties faced by the nursing staff with potential suggestions that may help to address these problems. Benefits include more open communication between staff and patients and potentially a more timely response to patient need which positively impacts levels of safety and satisfaction. Barriers include lack of staff engagement, and the environmental factors and pressures, within the ED setting.

\section{Relevance to clinical practice}

The findings from this study have the potential to inform knowledge and nursing practice, not only at this NHS Trust but also within other emergency departments more widely, particularly where the introduction of intentional rounding is being considered. Key items to consider are outlined below.

This study in alignment with the published literature has identified the importance of staff understanding the potential benefits of rounding, prior to trialling implementation. This may be achieved through and inclusive approach during the development of the rounding scheme.

Individual areas will need to give consideration to the most appropriate local strategies, as a one-size-fits all approach, with reference to rounding delivery, is unlikely.

Increasing workload through excessive documentation could contribute to difficulties with implementation. Efficient and effective ways of documenting the process of rounding therefore need to be agreed prior to the launch of a new scheme.

This project may also hold implications for future comparative research to be carried out in other emergency departments from other NHS trusts throughout the UK.

\section{Acknowledgements}

We would like to thank all at Health Education East Midlands for the opportunity to undertake this research as part of the research internship, which has been the invaluable first step into the world of a clinical academic career. Thank you also to all of the participants for their valuable time in taking part in this study. Many thanks to Ian McGonagle, Principal Lecturer at the University of Lincoln, for his much appreciated advice on the structure of the article.

\section{Contributions}

Study design: KK, RK; Data collection and analysis: KK; Manuscript preparation: KK, RK.

\section{Funding}

Project supported by the Clinical Scholar: Research Internship for Nurses, Midwives and Allied Health Professionals with Health Education East Midlands (HEEM), 2014 intake.

\section{References}

Aitken L, Burmeister E, Clayton S, Dalais C \& Gardner G (2011) The impact of nursing rounds on the practice environment and nurse satisfaction in intensive care: pre-test post-test comparative study. International Journal of Nursing Studies 48, 918-925.
Baker S (2012) Hourly rounding in the emergency department: how to accelerate results. Journal of Emergency Nursing 38, 69-72.

Banerjee J, Conroy S \& Cooke MW (2013) Quality care for older people with urgent and emergency care needs in UK emergency departments. Emergency Medicine Journal 30, 699-700.

Bartley A (2011) Making it Happen: Intentional Rounding. The King's Fund, London.

Berg K, Sailors C, Reimer R, O’Brien Y \& Ward-Smith P (2011) Hourly round- 
ing with a purpose. The Iowa Nurse Reporter. 12-14.

Berwick D (2013) Improving the Safety of Patients in England. National Advisory Group on the Safety of Patients in England. Department of Health, London.

Blakley D, Kroth M \& Gregson J (2011) The impact of nurse rounding on patient satisfaction in a medical- surgical hospital unit. Medsurg Nursing 20, 327-332.

Bourgault AM, King MM, Hart P, Campbell MJ, Swartz S \& Lou M (2008) Circle of excellence. Does regular rounding by nursing associates boost patient satisfaction. Nursing Management 39, 18-24.

Braide M (2013) The effect of intentional rounding on essential care. Nursing Times 109, 16-18.

Castledine G, Grainger M \& Close A (2005) Clinical nursing rounds part 3: patient comfort rounds. British Journal of Nursing 14, 928-930.

Cavendish C (2013) The Cavendish Review. An Independent Review into Healthcare Assistants and Support Workers in the NHS and social care settings. Department of Health, Leeds.

Ciccu-Moore R, Grant F, Niven B, Paterson $\mathrm{H}$, Stoddart $\mathrm{K} \&$ Wallace $\mathrm{A}$ (2014) Care and comfort rounds: improving standards. Nursing Management 20, 18-23.

D’Alessio E, Magsalin M, Neville KL \& Patten C (2010) Enhancing nursing's presence. Nursing Management 41 (12), 16-18.

Deitrick LM, Baker K, Paxton H, Flores M \& Swavely D (2012) Hourly rounding: challenges with implementation of evidence-based process. Journal of Nursing Care Quality 27, 13-19.

Dix G, Phillips J \& Braide M (2012) Engaging staff with intentional rounding. Nursing Times 108, 14-16.

Durazo M, Bedillion A, Monos E, Collins B, Hoenig N \& Wicks J (2014) "How does intentional rounding impact patient outcomes?". Nevada RNformation 23, 18.

Fitzsimons B, Bartley A \& Cornwell J (2011) Intentional rounding: its role in supporting essential care. Nursing Times 107, 18-21.

Ford BM (2010) Hourly rounding: a strategy to improve patient satisfaction scores. Medsurg Nursing 19, 188-191.
Forde-Johnston C (2014) Intentional rounding: a review of the literature. Nursing Standard 28, 37-42.

Francis R (2013) Report of the Mid Staffordshire NHS Foundation Trust Public Enquiry. Executive Summary. The Stationary Office, London.

Generals J \& Tipton P (2008) Rounding to increase retention. Nursing Management 39, 10-12.

Gillen S (2012) It is about being highly visible to your patients at least every hour. Nursing Standard 26, 12-13.

Harrington A, Bradley S, Jeffers L, Linedale E, Kelman S \& Killington G (2013) The implementation of intentional rounding using participatory action research. International Journal of Nursing Practice 19, 523-529.

Hicks D (2015) Can rounding reduce patient falls in acute care? An intergrated literature review. Medsurg Nursing 24, 51.

HSCIC (2015) Accident and Emergency Attendances in England - 2013-14. Health and Social Care Information Centre. Available at: http://www.hscic. gov.uk/searchcatalogue? productid $=172$ $00 \& \mathrm{q}=$ accident+and+emergency+dema nd+by+age\&sort=Most+recent\&size= 10\&page=1\#top (accessed 2 March 2015).

Hunt J (2012) Intentional rounding belies evidence-based practice. Nursing Standard 26, 26.

Hutchings M (2012) Caring around the Clock: rounding in practice. Nursing Times 49, 12-14.

Hutchings M, Ward P \& Bloodworth K (2013) 'Caring around the clock': a new approach to intentional rounding. Nursing Management 20, 24-30. 7p. 4.

Kendall-Raynor P (2012) PM vows to cut bureaucracy and introduce hourly nursing rounds. Nursing Standard 26, 6.

Keogh B (2013) Review into the Quality of Care and Treatment Provided by 14 Hospital Trusts in England: Overview Report. Department of Health, London.

Kessler B, Claude-Gutekunst M, Donchez AM, Dries RF \& Snyder MM (2012) The merry-go-round of patient rounding: assure your patients get the brass ring. Medsurg Nursing 21, 240-245.

Lowe L \& Hodgson G (2012) Hourly rounding in a high dependency unit. Nursing Standard 27, 35-40.
Lucas B \& Ahmad R (2010) Pro-active patient rounding: developing nursing practice to improve the quality of patient care. International Journal of Orthopaedic and Trauma Nursing 14, 227-228.

Lyons S, Brunero S \& Lamont S (2015) A return to nursing rounds - person centred or a task too far? Australian Nursing \& Midwifery Journal 22, 30-33. 4p.

Mason M (2012) More than a checklist. Nursing Standard 26, 20-21.

Mcdonnell A, Tod A, Bray K, Bainbridge D, Adsetts D \& Walters S (2013) A before and after study assessing the impact of a new model for recognizing and responding to early signs of deterioration in an acute hospital. Journal of Advanced Nursing 69, 41-52. 12p.

McEwen D \& Dumpel H (2010) Scripting and rounding: impact of the corporate care model on RN autonomy and patient advocacy. National Nurse 106, 20-27.

Neville K, Lake K \& LeMunyon D (2012) Nurses' perception of patient rounding. The Journal of Nursing Administration 42, 83-88.

NHS England (2015) A\&E Monthly Activity Statistics, NHS and Independent Sector Organisations in England. A $\mathrm{E}$ Performance and Activity. Available at: https://www.england.nhs.uk/statistics/ tag/ae-attendances/ (accessed 2 March 2015).

O'Leary Z (2010) The Essential Guide to Doing Your Research Project. Sage, London.

Ombudsman HS (2011) Care and Compassion? Report of the Health Service Ombudsman on Ten Investigations into NHS Care of Older People. Department of Health, London.

Ormston R, Spencer L, Barnard M \& Snape D. (2014) The Foundations of Qualitative Research. In Qualitative Research Practice (Ritchie J, Lewis J, McNaughton Nicholls C \& Ormston R eds). Sage, London, pp. 2-25.

Saleh B, Nusair H, Al Zubadi N, Al Shloul S \& Saleh U (2011) The nursing rounds system: effect of patient's call light use, bed sores, fall and satisfaction level. International Journal of Nursing Practice 17, 299-303.

Shepard LH (2013) Stop going in circles! Break the barriers to hourly rounding. Nursing Management 44, 13-15. 
Sherrod BC, Brown R, Vroom J \& Sullivan DT (2012) Rounding with purpose. Nursing Management 43(1), 32-38.

Snelling P (2013a) Intentional rounding: a critique of the evidence. Nursing Times 109, 20-21.

Snelling P (2013b) Ethical and professional concerns in research utilisation: inten- tional rounding in the UK. Nursing Ethics 20, 784-797.

Spencer L, Ritchie J, Ormston R, O'Connor W \& Barnard M (2014) Analysis: principles and processes. In Qualitative Research Practice (Ritchie J, Lewis J, McNaughton Nicholls C \& Ormston R, eds) Sage, London, pp. 269-293.
Subbe CP \& Welch JR (2013) Failure to rescue: using rapid response systems to improve care of the deteriorating patient in hospital. Clinical Risk 19, 611.

Woodard JL (2009) Effects of rounding on patient satisfaction and patient safety on a medical-surgical unit. Clinical Nurse Specialist 23, 200-206. 